\title{
O ELEMENTO ÉTNICO-RACIAL NAS CIÊNCIAS PSICOLÓGICAS: VERSÕES DE UMA CIÊNCIA (IM)PURA
}

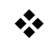 \\ Zuleika Köhler Gonzales \\ Universidade do Vale do Rio dos Sinos - Unisinos - Brasil \\ Neuza Maria Guareschi Correio \\ Universidade Federal do Rio Grande do Sul - UFRGS - Brasil
}

\section{Resumo}

Neste artigo, procuramos analisar como a psicologia foi concebendo o elemento étnico-racial como seu objeto de estudo, através das publicações feitas nos Arquivos Brasileiros de Psicologia entre 1949 e 1990. Para tanto, nos valemos dos estudos de Bruno Latour, Vinciane Despret e Isabelle Stengers para operar conceitualmente sobre as versões que se estabilizam nas articulações entre ciência, política e sociedade. Esses autores deslocam a produção do conhecimento de um modo tradicional de fazer ciência e história para uma abordagem cosmopolítica da ciência. Nos artigos pesquisados, delimitamos quatro eixos epistemológicos ou formas estabilizadas que compuseram as versões científicas do elemento étnico-racial neste estudo. São eles: Determinismo biológico; 2. Classificação e medição das ciências naturais; 3. A Psicotécnica dos Atributos da Personalidade, e; 4. Uma Fenomenologia do sujeito cultural. Apresentamos ainda as articulações político-científicas que possibilitaram a formação dos eixos que compõem as versões do étnico-racial.

Palavras-chave: Diversidade étnico-racial; Produção Científica; Ciência Cosmopolítica.

A diversidade étnico-racial no Brasil já foi alvo de discussão intensa de pensadores, políticos e profissionais liberais buscando o aprimoramento da população brasileira com vistas à constituição de uma forte e civilizada nação. Principalmente na virada do século XIX e primeira metade do século $\mathrm{XX}$, essa discussão tornou-se um grande investimento na adequação da população às demandas da produção econômica, como efeito dos novos arranjos em torno do capitalismo que se organizava a partir da revolução industrial na Europa. Nessa empreitada, o pensamento científico, que se estabelecia como forma de melhor racionalizar e desenvolver os Estados modernos, foi um grande aliado no projeto nacionalista de progresso econômico que por aqui vigorava. A questão étnico-racial torna-se pauta de governantes e intelectuais, na busca de uma solução para a crença difundida de que o atraso civilizatório da nação brasileira ancorava-se na sua múltipla composição étnica e racial. Com isto, um amplo processo de eugenia se instaura e vem sustentado pelos saberes científicos e, principalmente, pelas teorias racistas elaboradas no século XIX que, buscavam condições para um "melhoramento" racial progressivo no Brasil. 
Para visualizar a nossa diversidade étnico-racial no final do século XIX, encontramos no Recenseamento Geral do Império do Brasil de 1872 publicado em um Relatório do Núcleo de Pesquisa em História Econômica e Demográfica - NPHED - da UFMG em janeiro de $2012^{1}$, um total de 9.930 .378 pessoas inscritas no censo, dos quais, mais da metade dessa população eram negros e pardos. Um pequeno percentual - 3,9\% - foi apresentado no censo como 'caboclos', os indivíduos recenseados das populações indígenas. Este foi o primeiro censo brasileiro de abrangência nacional. E, segundo os autores do relatório (2012), este censo é considerado mais amplo que os de 1890 e 1900 e com maior exatidão e captação na cobertura dos dados.

Tabela 1: Recenseamento Geral do Império do Brasil de 1872

\begin{tabular}{|l|l|l|l|l|l|}
\hline \multirow{4}{*}{ Raças } & & Livres & Escravos & Total (\%) & TOTAL \\
\cline { 2 - 6 } & Brancos & 3.781 .110 & --- & $38,08 \%$ & 3.781 .110 \\
\cline { 2 - 6 } & Pardos & 3.331 .654 & 470.038 & $38,28 \%$ & 3.801 .692 \\
\cline { 2 - 6 } & Pretos & 919.674 & 1.040 .768 & $19,74 \%$ & 1.960 .442 \\
\cline { 2 - 6 } & Caboclo & 387.234 & --- & $3,9 \%$ & 387.234 \\
\cline { 2 - 6 } & & & & & $\mathbf{9 . 9 3 0 . 3 7 8}$ \\
\hline
\end{tabular}

Fonte dos dados: tabela formulada pelas autoras segundo os dados do Censo de 1872 e com dados ajustados pelo Método do Resultado Predominante - MRP - utilizado pelo NPHED apresentado no Relatório de 2012, p. 20.

De acordo com um estudo realizado por Botelho (2005), nos censos realizados no século XIX, havia uma preocupação em registrar a cor da população. Segundo o autor, predominantemente os levantamentos censitários deste período eram divididos em "brancos; a população de ascendência africana nascida no Brasil, mestiça ou não; e os pretos. Onde a população indígena assumia proporções significativas, essa categoria também se incorporava aos censos, descrita como caboclos". (Botelho, 2005, p. 326).

Importa dizer também quanto à nossa diversidade étnico-racial, que para fazer frente a substituição de mão-de-obra negra escravizada na agricultura nacional, os governantes e muitos latifundiários incorreram em um grande estímulo à imigração europeia principalmente na segunda metade do século XIX. Deste modo, agrega-se à composição étnico-racial formada no Brasil Colônia e Imperial com os nativos indígenas, colonos brancos e negros escravizados, o grande número de imigrantes europeus, árabes e japoneses que aportaram no Brasil sobretudo entre os anos 1890 a 1920, considerado o período de maior fluxo imigratório na virada do século XX, com um crescimento estimado em $11 \%$ na população do país. 
(LEVY, 1974, p. 49).

Os estudos acerca de nossa diversidade étnico-racial, vem se estabelecendo, predominantemente, no campo das investigações antropológicas. A interface com a psicologia, no entanto, vem ocorrendo desde sua injunção nos saberes médicos, jurídicos, pedagógicos e filosóficos que se institucionalizaram no campo acadêmico em nosso país, sobretudo em torno da higiene social que se formulou para desenvolver a população mestiça e analfabeta do país na virada do século XX. Os saberes psicológicos que começavam a se firmar, sobretudo pelo viés médico-sanitarista, também ocuparam lugar nessa mobilização político-social. Podemos dizer que, o investimento no "melhoramento" da população em face da sua diversidade racial sustentou-se fortemente nas ideias psicológicas, principalmente no conhecimento advindo das teorizações sobre o desenvolvimento humano. Do mesmo modo, este processo eugenista desencadeado sobre a população, encontrou na formalização da psicologia nas instituições acadêmicas e no estabelecimento de seus veículos de divulgação, como revistas especializadas, anais e congressos científicos, a legitimação de muitas formas racistas na sociedade, ancoradas ou invisibilizadas pelos saberes psicológicos.

É na busca de fortalecimento do Estado Brasileiro como nação, confluindo com a produção científica da virada do século XIX até meados do século XX que, neste artigo, procuramos analisar, como a psicologia foi concebendo o elemento étnico-racial como seu objeto de estudo. Para tanto, demarcamos quatro eixos epistemológico-científicos que demarcaram versões do étnico-racial em formas estabilizadas e atestadas pelo campo da ciência nas produções textuais publicadas na primeira revista de psicologia no Brasil, os Arquivos Brasileiros de Psicotécnica ${ }^{2}$, posteriormente chamada Arquivos Brasileiros de Psicologia. São estes os quatro eixos: 1. Determinismo biológico; 2. Classificação e medição das ciências naturais; 3. A Psicotécnica dos Atributos da Personalidade, e; 4. Uma Fenomenologia do sujeito cultural. Uma ressalva quanto aos eixos faz-se necessária: eles não são cronologicamente lineares e nem excludentes. Para denominar o eixo do determinismo biológico, entendemos que os artigos mapeados sob este eixo, desdobraram-se em um processo mecânico, "segundo um encadeamento inexorável de causas e efeitos" (Figueiredo, 2010, p. 26) a partir de dotes hereditários-biológicos explicando as diferenças e a hierarquia entre raças. Já no eixo que denominamos de classificação e medição das ciências naturais, encontramos uma matriz que "busca a ordem natural dos fenômenos psicológicos e comportamentais na forma de classificações e leis gerais com caráter preditivo" (Figueiredo, 2010, p. 25). Importa dizer que, o determinismo biológico na explicação da subjetividade humana conjuga-se às tentativas de se fazer da psicologia uma ciência natural utilizando-se da 
construção de hipóteses formais, da previsão condicional em cálculos e do teste de mensuração, ou seja da lógica experimental formulada no seio das ciências naturais Já o terceiro eixo, o da Psicotécnica dos Atributos da Personalidade, assim denominamos por entender que nos artigos analisados, visualiza-se uma matriz epistemológica da psicotécnica como legitimação científica em práticas de controle exercidas socialmente. A psicotécnica se configura, principalmente, em técnicas psicométricas que necessitam ter "aparência de cientificidade; [...] a sua mera existência transmite a seguinte mensagem: uma tecnologia psicológica é possível e não há mal algum em usá-la (a ciência garante). Neste contexto é que o verdadeiro significado da pesquisa pura pode ser apreendido" (Figueiredo, 2010, p. 30). E por fim, quanto ao quarto eixo mapeado, uma Fenomenologia do sujeito cultural, assim o denominamos por entender que os artigos ali nomeados, sustentam-se por "apreender os eventos psíquicos de acordo com a sua especificidade - que é a de não serem coisas no mundo, mas atos constitutivos do mundo"(Figueiredo, 2010, p. 36), visando "compreender e interpretar as modulações da consciência empírica, vale dizer, as formas de relacionamento sujeito/objeto concretamente vivenciadas" (Figueiredo, 2010, p. 36) e que dão um quadro de referências para se entender o sujeito em questão explicitando os elementos e a norma implícitos em seu mundo que conferem sentidos aos seus atos e vivências.

$\mathrm{Na}$ composição dos elementos étnico e racial nos artigos pesquisados, podemos visualizar os quatro eixos em um campo de análise - o elemento étnico-racial -, no qual assinalamos sete (7) artigos entre 1949 e 1990 em que a conjunção entre o elemento étnico e racial organizam formas de se pesquisar ou ainda, compõem um pensamento epistemológico nas ciências psicológicas.

Com este estudo, queremos intensificar a problematização de como nos colocamos e versamos sobre etnicidade e raça nas nossas produções acadêmicas, justamente por entender que os modos pelos quais elaboramos as questões sociais nas práticas psicológicas e na formalização de um saber, proferem e constituem inúmeras formas que marcam e afirmam as nossas diferenças. Esperamos assim, fomentar o debate acadêmico no campo da psicologia sobre o investimento e a tomada do elemento étnico-racial como seu objeto de estudo, entendendo, como premissa, que a discussão étnico-racial no Brasil sempre se pautou por uma concepção eurocêntrica e colonialista, pelo menos desde a primeira colonização das Américas e das terras brasileiras pelos europeus em meados do século XVI. Mapeando os caminhos até então trilhados na produção acadêmica, talvez possamos vislumbrar com os questionamentos colocados em nossos estudos, outras versões mais localizadas, simétricas e contrastantes.

Para nos auxiliar nesta investigação, buscamos nos estudos de Bruno Latour, Vinciane 
Despret e Isabelle Stengers ${ }^{3}$ algumas chaves conceituais para operar sobre as versões que se estabilizam nas articulações entre ciência, política e sociedade. Esses autores deslocam as abordagens de um modo tradicional de fazer ciência e história para uma visão cosmopolítica da ciência; ou seja, eles concebem o fazer científico como uma prática social articulada às negociações acadêmicas e políticas que vão eleger e autorizar determinadas práticas científicas, decorrendo daí a produção deste ou daquele objeto, inscrito em versões localizadas e articuladas a toda uma rede de negociação. É por isto, que eles recusam o acordo moderno que estipula, separa e define o que é objetivo - como sendo da ordem da natureza e o que é subjetivo - como sendo da ordem do social. Neste sentido, entendem que natureza e sociedade não são polos separados e opostos, e nem o discurso sobre as coisas, chamado de ciência ou técnica se distancia da realidade, como se estivesse em uma outra instância a ser acessada pela mente brilhante de algum cientista. Muito menos, o discurso científico é portador de uma pureza e dissimetria com relação ao discurso sobre os homens, na dimensão política. Ao contrário, concebem essa fabricação e distinção entre natureza e sociedade, como um longo e árduo trabalho de distribuição dos componentes do mundo entre natureza e sociedade. É daí, das mobilizações e negociações produzidas neste trabalho de distribuição que múltiplas versões sobre o que se estabiliza nesta composição sempre móvel, irão se fazer. Versões político-científicas que podem ser entendidas como algo que se cultiva, que se faz e que se produz na articulação entre ciência, política e sociedade.

Pensar com os estudos empreendidos por Latour, Despret e Stengers nos faz recolocar o modus operandi do fazer científico. Esses autores, como já assinalado anteriormente, desfazem a divisão entre natureza e sociedade na descrição do que se refere à ciência. Desta forma, eles questionam a declaração de validade para uma ciência que se atesta só e unicamente pela objetividade dos parâmetros metodológicos de medição laboratorial e de outro lado, uma ciência que se declara autenticamente social por considerar a subjetividade no humano e na sua inserção no mundo das coisas. Com isto, desfaz-se a divisão que separa o quesito objetividade do lado da natureza e, subjetividade do lado da cultura ou da sociedade. Interessa sim, decompor e traçar as linhas que demarcam associações heterogêneas entre humanos, seus artefatos e as coisas do mundo, formando entidades prontas a se associarem novamente em outras formas sempre mutantes, mescladas ou impuras.

Com isto, decompondo as linhas que traçaram as versões sobre etnicidade e raça nas produções acadêmicas em psicologia, entendemos que este trabalho pode nos fazer pensar e resultar em formas e discursos mais equânimes nas práticas psicológicas, se considerarmos que o contraste entre versões nos possibilitam um deslocamento do convencional 
hegemônico, sobretudo se entramos na discussão sobre povos e etnias.

\section{Desdobrando o étnico-racial com os estudos cosmopolíticos da ciência}

Para começar a desdobrar as versões do elemento étnico-racial no período em que o saber psicológico vai se configurando como um campo formal das ciências no Brasil, cabe explicitar o porquê da escolha dos Arquivos Brasileiros de Psicologia para servir de campo de investigação. Escolhemos fazer um percurso através das edições dos Arquivos Brasileiros de Psicologia, justamente por ser a publicação no campo das ciências psicológicas de maior longevidade no país, também por declarar como escopo "acolher e difundir a diversidade das produções científicas e profissionais da Psicologia e áreas afins", o que entrevê a possibilidade de transitar por uma variada gama de concepções e versões sobre as práticas psi. Além disso, a própria fundação da revista evidencia os laços entre as práticas científicas, a sociedade e os ditames políticos e econômicos referendados pelos estudos cosmopolíticos da ciência.

Sustentando os eixos que estipulamos como linhas que compõem o elemento étnicoracial nos $\mathrm{ABPs}^{4}$ até a década de 1980, um conjunto de pelo menos 2 psicólogas, 2 testes, uma instituição de formação econômico-acadêmica e um periódico se mesclam hibridamente. São eles: Aniela Ginsberg, Monique Augras, O teste projetivo de Rorschach, o teste miocinético PMK de Mira y López, a Fundação Getúlio Vargas e os Arquivos Brasileiros de Psicologia. Eles de alguma forma, estabelecem os quatro eixos epistemológico-científicos que traçam o elemento étnico-racial em concepções que, sobretudo, se declaram válidas pelo rigor de exatidão metodológica e operacional - sem contaminação por outras formas, sejam elas políticas, econômicas, etc. mantendo a neutralidade da ciência - nos procedimentos investigativos e no registro do fato científico, puro, neutro e racional.

Apesar da articulação sócio-política no fazer científico presente nessa composição entre autores, testes, instituições e periódicos, a preocupação dos autores dos sete artigos escolhidos para análise neste estudo, centra-se em atestar um resultado válido para a ciência em critérios que separam o que é da ciência e o que é do social. Atentos às críticas dos autorizados na razão científica, sobretudo, os pesquisadores das ciências naturais com seus métodos positivistas, os psicólogos publicam seus trabalhos acadêmicos, evidenciando, sobretudo, um caráter psicodiagnóstico e psicopatológico em testes de mensuração da inteligência e da personalidade comparando grupos étnicos e raciais, principalmente, nos artigos que são editados até a década de 1970 nos ABPs. Entre as décadas de 1970 e 1990, 
mesclam-se concepções embasadas na psicotécnica e nas descrições fenomenológicas da cultura. Apenas como informação, pois não vamos nos deter nos rumos tomados nas publicações dos ABPs após 1990, encontramos nas edições posteriores e, principalmente a partir de 2002, uma conotação do elemento étnico-racial mais voltada para políticas identitárias e para a afirmação dos direitos em políticas de ação afirmativa, apresentando um caráter mais de análise das condições sociais do que de análise tipológica dos indivíduos como nas décadas precedentes.

Entre 1951 e 1968, três artigos mapeados neste estudo, primam pelo determinismo biológico com dotes hereditários explicando as diferenças e a hierarquia entre raças, mesclando-se à localização geográfica da população de acordo com a sua maior densidade populacional quanto ao elemento étnico-racial; buscam ainda, explicar essa hierarquia pela classificação e medição proveniente das ciências naturais, o que se concretiza na utilização do esquema métrico para ratificar a discriminação das capacidades mentais entre diferentes grupos étnicos e raciais. Delineamos também nesses três artigos, a ênfase na psicotécnica dos atributos da personalidade para compor a caracterização étnico-racial dos indivíduos.

No primeiro artigo, "Comparação entre os resultados de um teste de nível mental aplicado em diferentes grupos étnicos e sociais" de autoria de Aniela Ginsberg e publicado em 1951, a autora parte dos resultados de uma pesquisa realizada anteriormente pelo COJ (Centro de Orientação Juvenil do Departamento da Criança do Ministério da Educação e Saúde, do RJ) nos anos de 1947 e 1948. A pesquisa do COJ, que serviu de laboratório para a pesquisa de Ginsberg, consistiu em testar o nível mental de 4.610 alunos de "escolas secundárias oficiais" (p. 27) através de uma adaptação do Teste de inteligência de Terman. O COJ realizou a pesquisa em cinco cidades brasileiras: Rio de Janeiro, Fortaleza, Salvador, Belo Horizonte e Porto Alegre. Chamou a atenção de Ginsberg, a grande diferença de nível médio de inteligência nos diferentes estados brasileiros, através de suas respectivas cidades. No Rio de Janeiro e em Porto Alegre, as notas médias ficaram em 88,46 e 88,74 respectivamente. Já em Fortaleza e em Salvador, ficaram em 59,90 e 67,80 respectivamente. Estes dados tão precisos levaram a pesquisadora a querer comparar os resultados dos testes de acordo com o "meio sócio-econômico dos alunos examinados" (p. 28) e se havia variações de acordo com as diferenças étnicas dos alunos provenientes de um mesmo meio social. Assim, a nova pesquisa, agora elaborada por A. Ginsberg (1951) sobre os dados da pesquisa do COJ, consistia em: "1. Verificar se os resultados dos testes variavam de maneira significativa em relação ao meio sócio-econômico dos alunos examinados”, e: “2. Verificar se dentro do mesmo meio social podia-se notar uma variabilidade significativa entre os resultados obtidos por alunos de 
diferentes grupos étnicos".

A pesquisadora Aniela Ginsberg escolheu ao acaso, 500 testes realizados em cada um dos estados anteriormente pesquisados pelo COJ. Ela queria "conseguir grupos de jovens comparáveis de alguns Estados brasileiros, bem diferenciados geográfica e etnicamente" (Ginsberg, 1951, p. 28). As escolhas se deram da seguinte forma: "Bahia, devido ao número considerável de alunos negros e mulatos; Ceará - por causa do elemento indígena na população nordestina; Rio Grande do Sul, como estado sulista, com a população quase exclusivamente branca (falamos aqui apenas da população escolar” (p. 28); e, também foi levado em conta, o Rio de Janeiro, que neste momento sediava o Distrito Federal, ou seja, a sede do Governo Nacional "como representante do Brasil Central e da grande Capital" (p. 28), que, no entanto, consta sem referência à condição étnico-racial de sua população.

Além, desta divisão geográfica, os alunos também foram classificados em seis grupos, segundo a aparência física racial: 1. Jovens completamente brancos; 2. Brancos, com alguma mistura racial, levemente mulatos; 3. Mulatos; 4. Negros, com alguma mistura com brancos; 5. Completamente negros; e, 6. Jovens índios ou com uma mistura com índios. Esta classificação foi feita na base dos seguintes critérios de cunho biológico: cor da pele; textura do cabelo e forma do nariz.

Os critérios étnico raciais depois foram analisados em comparação com grupos econômicos através da profissão ou ocupação profissional dos pais dos alunos. Como resultado, o que se apresentou na pesquisa, foi uma grande diferença entre a presença de alunos classificados na pesquisa como brancos e negros no ambiente escolar nos Estados pesquisados; tal resultado vinculou-se às questões sócio-econômicas. Neste sentido, a investigadora declarou que:

O número reduzido de crianças de cor em nosso estudo, mesmo nas cidades com numerosa população de cor, como Salvador e Rio de Janeiro, explica-se provavelmente por fatores sócio-econômicos. Tratando-se aqui de alunos de escolas secundárias, já na idade em que possam trabalhar. (Ginsberg, 1951, p. 35).

Depois quanto à variância no grau de diferenças entre grupos étnicos, os piores resultados ficaram associados aos alunos da raça negra. Sobre esses resultados a cientista afirmou que:

Os resultados médios pioram consideravelmente entre os alunos de cor mais escura pertencentes a classe média. [...] Entre os filhos de operários especializados os resultados pioram entre os de cor mais escura em relação com os brancos e os mais claros. [...] Podemos dizer que, em todos os grupos sociais estudados obtiveram os 
melhores resultados os alunos brancos, em segundo lugar vêm os mulatos claros (quase brancos), em seguida, o grupo total de mulatos, depois as crianças com elementos étnicos índios e em último lugar os alunos pretos ou quase pretos. (Ginsberg, 1951, p. 36, 37 e 38)

É interessante que no mesmo ano, 1951, em que A. Ginsberg edita os resultados de sua pesquisa, o cientista e educador J. Roberto Moreira publica o artigo "A noção pluralista de fato psíquico" nos Arquivos Brasileiros de Psicologia exaltando a aplicabilidade da ciência para obter resultados imediatos para as necessidades impostas pela ação humana e pelos fatos naturais. E, nessa busca de soluções para os "problemas cruciantes da vida individual e da vida coletiva"(p.7) o que interessava para as ciências propriamente científicas, no dizer do cientista e educador, é a variabilidade. Segundo ele, nos procedimentos científicos modernos não ocorreria unidade nem coerência nas hipóteses formuladas para orientar uma pesquisa contrapondo-se aos princípios anteriores em que se afirmava o científico pela invariabilidade. Disse ainda que, as hipóteses formuladas para orientar os estudos, seriam feitas sob um plano plural, com diferenças irredutíveis umas às outras. No que isto apontava para a variabilidade nas pesquisas científicas, assim como na busca por evidenciar a variabilidade étnico-racial no trabalho realizado por A, Ginsberg?

Chamando em causa o positivista Comte, o cientista Moreira (1951), declara que se antes "conhecer era operar buscando as relações invariáveis de sucessão e de similitude para constatar regularidades e constâncias", os cientistas da natureza demonstraram no século XX, principalmente a partir de Einstein, que o que importa é decifrar as irregularidades e inconstâncias nos dados estatísticos ou nas curvas geométricas. Assim, afirma Moreira (1951): “A lei científica tende a ser a expressão de uma distribuição de frequência de diferenças". E, desta forma, o variável substitui o invariável nas ciências da natureza. E, se as ciências psicológicas buscavam legitimar-se nos cânones científicos inscritos nas leis da natureza, vê-se aí no trabalho de Ginsberg uma correlação para adequar-se aos mandatos político-científicos vigentes. Reconhecer-se como ciência implicava em utilizar fielmente os passos metodológicos das ciências da natureza para a medição das irregularidades ou variabilidades do objeto pesquisado.

Desta forma, o determinismo biológico marcado pelos órgãos do corpo, na forma do cabelo, do nariz, estatura, etc. associado à variabilidade das estatísticas de um registro científico, atestam uma determinada versão do étnico social autorizada politicamente e socialmente pelas instituições do fazer científico. A cor das pessoas se inscreve como variável, junto às categorias de sexo, escolaridade e condição sócio-econômica, resultando em 
conclusões que diferenciam hierarquicamente os grupos étnico raciais.

Ao mesmo tempo, natureza e civilização vão se estabelecendo e se afirmando em campos opostos, com a utilização da psicotécnica através das testagens de nível mental e da reação física. Com um caráter psicofísico, os testes psicológicos utilizados nas investigações que abarcavam o elemento étnico e racial, buscavam comparar com os grupos de feição europeia, as aptidões sensoriais de outros grupos, tais como acuidade visual, tempo de reação para estímulos sonoros e também a capacidade de reação a estímulos mentais e cognitivos, tais como julgamento, memória, classificação.

Com uma postura bastante crítica à utilização da psicotécnica, sobretudo nas pesquisas com grupos étnico-raciais, a pesquisadora M. Augras (1990) denuncia que "a aplicação de testes psicológicos em grupos cujos padrões culturais diferem amplamente dos grupos a partir do qual os testes foram elaborados, pouco ou nada acrescenta à psicologia ou à antropologia". A autora elaborou sua crítica a partir das investigações psicológicas em três grupos étnicoraciais: com a aplicação de testes psicofísicos por Rivers em ilhéus do estreito de Torres; a aplicação do Rorschach e PMK por Baldus em índios Kaingang; e a aplicação do Rorschach em sacerdotisas dos cultos afro-brasileiros do Recife, por Ribeiro. E Concluiu que o uso de técnicas projetivas, nessas condições, inscreve-se numa vertente colonialista utilizado para comparar os povos "exóticos" com o homem branco considerado bem mais evoluído e próximo da perfeição do que os povos colonizados, que por sua vez, estariam mais próximos da natureza, de acordo com os resultados obtidos. Afirma-se também neste caso, uma supremacia da racionalidade científica por um pensamento ideal concernente a uma lógica da objetividade presente nas ciências da natureza em detrimento da produção do conhecimento que se faz na empiria da razão corporal ou de uma natureza não decodificada pela razão. Este é o caso do relato feito no segundo artigo que analisamos a seguir.

No artigo "Os índios guaraunos através do psicodiagnóstico miocinético do Dr. Mira y Lopez" escrito em 1955, o venezuelano Belarmino Larez produz como requisito para a formação em psicotécnica realizada no ISOP novas afirmações sobre o elemento étnico-racial. Exaltando Emílio Mira y Lopez, o diretor do ISOP e criador do teste PMK - miocinético, o venezuelano declara em primeiro lugar que: "O teste miocinético (...) é um teste já muito difundido nos círculos modernos de todo o mundo, como técnica de investigação do núcleo básico e reacional da personalidade” (p. 29). E depois, que: “(...) seu campo de aplicação transpôs o especificamente psiquiátrico e vai se ampliando com a contribuição de numerosas aplicações realizadas em grupos humanos normais, cárceres e tribos selvagens” (p. 29). O objetivo da aplicação do teste miocinético na sua pesquisa é "conhecer a personalidade do 
guarauno, não só no plano temperamental, como também no caracterológico” (p. 31). E para isto, Larez (1955) formulou 5 objetivos, tendo como o primeiro deles: "Conhecer fundamentalmente o componente de agressividade do guarauno, como base para comparação posterior que fazemos desse índice com o adulto normal de nosso meio e o da classe homicida" (p. 31). Depois, o pesquisador também queria conhecer "o grau de emotividade" dos Guaraunos, o "tônus psicomotor" e o "tônus vital” dos indígenas para estabelecer "o sentido vivencial do índio" (p. 31). É evidente a associação entre a identificação e classificação de categorias psicológicas com a formulação de uma classe de pessoas desaprovadas e/ou desqualificadas. O indígena exótico neste estudo é afirmado como um anormal perigoso e questionável quanto às suas produções de sentido, de acordo com a sua "emotividade" ou tônus psicomotor. Buscando referência nos elementos biológicos de caracterização para diagnósticos nosológicos, como grau de reação física ou tônus muscular, caracterizações psicológicas vão se produzindo para legitimar a discussão científica do elemento étnico-racial a partir das ciências psicológicas.

Ainda no terceiro artigo analisado, "Características de personalidade em dois grupos étnicos, através do psicodiagnóstico miocinético", Alice Galland Mira y López, psicóloga do ISOP/FGV e esposa de Emílio Mira y López, proclama a importância de se pesquisar as diferenças étnico raciais na sociedade, apesar de ressaltar a dificuldade para a ciência de se lidar com uma população miscigenada como a brasileira. Diz ela assim: "a organização da amostra (da pesquisa) tornou-se difícil, pois no ambiente brasileiro, não há grupos que se possam classificar como autenticamente puros" (Mira, 1968, p. 22). Nas conclusões, a autora preconiza a fisiologia do corpo como determinante para a categorização psicológica dos comportamentos e para a aplicabilidade da ciência na adequação dos grupos sociais: "Pareceme que o aspecto psicológico de maior excitabilidade no grupo predominantemente Preto poderia assinalar um aspecto neuro-fisiológico peculiar deste grupo. Cabe perguntar se esta característica é unicamente fisiológica ou se as influências do ambiente externo poderiam alterar essas condições endógenas" (Mira, 1968, p. 30).

Depois, a psicóloga afirma para os psicólogos: "o fato de ter encontrado no PMK diferenças significativas entre estes dois grupos étnicos (brancos e pretos), parece-me que nos coloca em face de um problema do qual o psicólogo tende a evadir-se com o temor de estar fazendo 'discriminação' racial” (Mira, 1968, p. 30). E, para concluir, dirige-se para a sociedade, com a autoridade de um dizer objetivo e, portanto, atestado pela ciência vigente: 
de lamentáveis acontecimentos históricos, onde traços característicos de grupos étnicos foram considerados, dentro de noções preconcebidas, o que tem impedido o estudo objetivo dos problemas. O reconhecimento de diferenças étnicas não implica em prejudicar os direitos humanos. Muito ao contrário, poderá fornecer recursos para melhor estimar as exigências raciais de cada grupo.

No entanto, a questão posta sobre as diferenças étnicas validadas pelo teste miocinético em torno da avaliação psicofísica dos sujeitos pesquisados, mesmo trazendo em sua composição o discurso em favor dos direitos humanos, afirmam uma diferença assimétrica e desfavorável entre as raças, para não dizer, do lamento expresso pela investigadora por não existir raças puras no Brasil para a constatação e intervenção das verdades científicas.

Depois, nos artigos que vão do final dos anos 1970 até os anos 1990, a versão fenomenológica se faz presente junto aos artigos produzidos sob a tradição da psicometria nos testes de interpretação dos atributos da personalidade. As versões sobre o elemento étnicoracial compõem-se nos modos como os pesquisadores vão articulando epistemologicamente seus trabalhos acadêmicos.

É aí que a versão fenomenológica de se apresentar o elemento étnico-racial toma lugar nos trabalhos de Augras. Configura-se em um formato de cunho mais filosófico nas ciências psicológicas, ou seja, de uma leitura dos fenômenos psicossociais que vem para privilegiar o sentido dado por um sujeito a todos os seus objetos, incluindo o seu corpo, a sua personalidade, bem como às atividades cotidianas da cultura a partir das percepções fenomenológicas de um ego transcendental e, posteriormente, da experiência do corpo vivido.

Com base em uma análise feita pelo professor Zilles (2007) sobre o pensamento de Husserl, autor chave no pensamento fenomenológico, encontramos que o objetivo do filósofo foi o de superar a oposição entre objetivismo e subjetivismo com a proposta de estipular a propriedade dos atos de pensar, perceber etc., a partir do seu conteúdo de sentido, ou seja, do pensado e percebido. Se até o final do século XIX, ainda reinava um fascínio por se produzir conhecimento objetivo a partir das ciências da natureza, Husserl busca integrar esse objetivismo com uma subjetividade que se atribui ao cognoscente. No entanto, segundo Zilles (2007), Husserl sucumbe a um psicologismo, que seria conceber a lógica formal como um conjunto de normas que valeriam para todo o pensamento certo, ou dito de outra maneira, a lógica se fundamentaria na psicologia.

Integrando a objetividade da lógica formal com a subjetividade da experiência, Husserl afirma que "as proposições lógicas contêm verdades necessárias, puramente ideais; [já] as proposições da psicologia generalizam interpretações da experiência. A psicologia 
pressupõe a existência de seus objetos e a lógica não" (Zilles, 2007, p. 217). O filósofo irá distinguir dois campos da lógica pura: a lógica das categorias de significação (como conceito, proposição, conclusão, etc.), referindo-se ao sujeito cognoscente ou ao que ele denominou de psicologia e, a lógica das categorias objetivas (como objeto, conteúdo, unidade, pluralidade, relação, etc.) constituindo uma esfera de essências ideais, com um sistema de categorias semióticas e outro sistema objetivo para o qual o primeiro se dirigiria havendo assim uma correlação entre ambos. A reflexão fenomenológica assim, partiria da "correlação de cada cogito com seu cogitatum, que nunca é um objeto isolado, mas desde logo deveria ser concebido como objeto em seu mundo" (Zilles, 2007, p.2017). Ou seja, o objeto do pensamento só poderá ser concebido e pensado se estiver vinculado a um tempo-espaço para formar um sentido para o sujeito cognoscente.

É desta forma que o pensamento fenomenológico virá em busca de condições que possibilitam a ciência ou a Teoria em geral. Pela crítica ao puro psicologismo Husserl pensa a propriedade dos atos de pensar, perceber etc., a partir do seu conteúdo de sentido, ou seja, do pensado e percebido. É neste viés epistemológico que a psicóloga Monique Augras se coloca. Servidora também do ISOP/FGV, Monique dialoga com as questões da cultura. Reverbera em seu trabalho o que ela chama de uma psicologia da cultura.

Mas, junto à versão fenomenológica trabalhada por Augras - de cunho mais filosófico na configuração do étnico-racial nas ciências psicológicas -, integra-se também uma versão assentada nas significações inconscientes em um artigo visando a interpretação das estruturas inconscientes e, possivelmente, consideradas mais primitivas junto aos indígenas das tribos Xavante e Bororó. Com o título "A estrutura psicopulsional de um grupo indígena brasileiro", os pesquisadores da Universidade de Brasília, E. Romankiewicz e R. Bucher (1982) publicam um artigo buscando identificar estruturas psicológicas universais entre aqueles considerados civilizados e os não-civilizados. Desta forma, redigem o artigo apresentando os resultados da aplicação do teste projetivo de Szondi em 65 índios Xavantes e Bororós (MT). Declaram que: "Os resultados demonstram resultados significativos entre os sexos, notadamente no vetor dos afetos. As mulheres manifestam mais hostilidade, bem como fortes tensões libidinais. No índex sexual, ambos os sexos apresentam proporções mais masculinas" (p. 110). Por fim, demonstram a preocupação em como adequar os indígenas à sociedade considerando suas características psicológicas inconformes ao ideário de civilização ocidental evoluída, quando dizem: "Parecem marcar a participação aos valores da coletividade, o que difículta a individualização, própria às culturas ocidentais. Reações de culpabilidade e de consciência moral interiorizada são quase ausentes. A comparação como uma população africana revela 
estruturas muito semelhantes" (p. 111). Esta seria uma versão do elemento étnico-racial pela via das significações, contrária ao que a pesquisadora Monique Augras preconizou em seus trabalhos, visto que a psicotécnica dos testes projetivos segundo parecer da autora, vinculavam-se a modelos culturais diversos daquele dos grupos em que foram aplicados, apresentando uma inadequação quanto o conhecimento produzido. Ou seja, o sentido elaborado pelos diversos grupos étnico-raciais na aplicação do teste, não correspondia ao que se preconizava como resultados esperados no padrão de respostas estabelecido previamente.

Compondo o universo dos trabalhos científicos na psicologia com outras versões, Monique Augras, como já apontamos anteriormente, diverge do que até então se encaminhava pela afirmação da objetividade centrada nas ciências da natureza. Com o título de "O objeto do desejo. A identificação do dono da cabeça no candomblé”, a psicóloga publica um artigo em 1979, aproximando-se das questões étnicas pela via religiosa. Tem por objetivo "verificar em que medida a descrição dos orixás corresponderia a uma tipologia intuitiva para fazer a equivalência em um psicodiagnóstico com a descrição de um traço de personalidade de cada filho do terreiro".

Depois, em 1985, Monique publica "Problemas teóricos (e metodológicos) da pesquisa psicológica em comunidades de terreiro", um texto derivado de uma apresentação no III Congresso da Associação Latino-americana de Estudos Afro-Asiáticos, ocorrido no RJ, em agosto de 1983. Com este trabalho, a pesquisadora se pergunta "quais são os requisitos necessários para a realização, por psicólogos, para a pesquisa no campo das religiões afrobrasileiras?" O artigo é elaborado como uma proposta de uso do método fenomenológico. Fazendo críticas ao evolucionismo biológico nos encaminhamentos psicológicos, como na aplicação de testes para mensuração psicopatológica e da personalidade, a psicóloga indica a fenomenologia como opção de mudança. Diz ela assim: "A fenomenologia destaca três pontos: acontecimento, convivência e testemunho. Privilegia o encontro e rechaça a pretensão interpretativa. (...) O outro deixa de ser objeto, passa a ser também sujeito do conhecimento".

E, conectando-se com os estudos encaminhados pelo campo da antropologia menciona que os trabalhos clássicos dos antropólogos sobre as comunidades de terreiro recorreram a conceituações oriundas de teorias psicológicas, até psicopatológicas, como Nina Rodrigues que utilizou Charcot (1900) para falar do transe místico; depois, Artur Ramos (1934) que usou o modelo psicanalítico para interpretar os mitos iorubás e considerou o transe como um fenômeno patológico. Já no antropólogo Herskovits (1973), Monique diz que ali encontra uma normalidade do transe místico presente nos terreiros de culto africano. Postulando uma outra versão para as investigações psicológicas referentes ao elemento étnico-racial, a 
psicóloga M. Augras amplia o discurso das ciências, aproximando-se de outros saberes formalizados, como a antropologia, e ao mesmo tempo problematizando os encaminhamentos e práticas psicológicas que não se voltam para o reconhecimento do outro em sua historicidade e no seu próprio estranhamento.

Mapear as linhas e eixos que compõem esses artigos até a década de 1980 nos Arquivos Brasileiros de Psicologia, explicitam os caminhos tomados no campo da psicologia quanto às concepções epistemológico-científicas formuladas para sustentar os artigos que tratam ou abordam o elemento étnico-racial em suas páginas. As versões sobre o étnico-racial afirmadas nos textos estudados, ora se pautam por uma prerrogativa de objetividade universal nos procedimentos experimentais e nas técnicas de mensuração para se alcançar resultados pertencentes à lógica formal de uma ciência pura, racional e inteligível e, ora proclamam uma subjetividade universal inscrita em um idealismo transcendental que pressupõe a supremacia do sujeito na pureza de sua consciência concebendo uma única realidade possível, ou seja, a realidade dos fenômenos - o aparecimento das formas essenciais do ser e das coisas - que se impõem para o pensamento através do "mundo vivido" pelo sujeito reflexivo.

\section{Articulações entre o fazer científico psicológico e o campo político na constituição do étnico-racial}

Retomando as condições e as articulações entre ciência e política que propiciaram a instalação da Fundação Getúlio Vargas como arauto das ciências psicológicas na primeira metade do século XX, voltamos agora para os movimentos políticos que inscreveram o saber psicológico na formação de uma nação civilizada e evoluída.

No início do século XX, a intelectualidade brasileira de norte a sul do país, dividia-se entre aqueles que tinham no parâmetro europeu um projeto de nação, visando a modernizar, civilizar e integrar a sociedade de acordo com o ideário propagado pelas tradições europeias, e, por outro lado, encontravam-se aqueles que procuravam compreender o país em seus próprios termos, investindo contra o modismo e a imitação das ideias. No entanto, parece que a ideia de progresso da nação vinculada ao estabelecimento da ciência e de um trabalho racional mantinha-se presente em ambos os lados. nos parâmetros desenvolvimentistas do mercado livre ou do pensamento liberal que se fortalecia na Inglaterra - matriz comercial e industrial dos países ocidentais - e na América do Norte como solução para as questões sanitárias e educacionais entre outros males que afligiam a população brasileira. É o caso de Arthur Neiva, cientista do Instituto Osvaldo Cruz e crítico literário que considerava a 
mentalidade de nossos intelectuais e das elites dirigentes, impregnada de retórica e lirismo e que pouco faziam pelo progresso da nação (Souza, 2009). Apesar de crítico da imitação brasileira do pensamento europeu, principalmente francês, Neiva empolgava-se com o pragmatismo inglês e a possibilidade de adotarmos o caminho do trabalho para transformarmo-nos em homens de ação, em industriais e comerciantes de sucesso e assim, colocarmo-nos nas vias do desenvolvimento nacional. Grande defensor da imigração europeia para desenvolver a nação, pensava com isto, levar as benesses do progresso e da civilização para o interior sertanejo e ao mesmo tempo, incorrer no branqueamento da população brasileira.

Um ponto importante então nesta cruzada política de formação da nação brasileira foi o processo de eugenia que se instaurou no país na virada do século XIX para o século XX. A psicologia entra aí como prática científica aliando-se ao viés biológico de investimento no corpo - como apresentado em uma das versões apresentadas em análise na seção anterior deste artigo., Tal aliança vem encabeçada pela medicina como a principal estratégia de melhoramento das populações por meio da higiene social. O determinismo genético pautou a emergência de uma psicologia que se configurava nos moldes das ciências físicas e, portanto, da natureza, que dominavam o debate científico no final do século XIX. Não é à toa que, em 1890, James M. Cattell, ardoroso defensor das capacidades mentais inatas ou herdadas, seguindo Darwin e, principalmente F. Galton, publica na revista Mind nos USA, o artigo intitulado "Mental tests and measurements" abrindo portas para a instauração da psicotécnica na utilização das ciências psicológicas para o incremento e investimento nas populações. Nesse texto, como um ícone da produção científica no século XIX, Cattel diz que "a psicologia não pode atingir a exatidão e a certeza das ciências físicas, a não ser que se apóie num fundamento de experimento e mensuração. Um passo nesse sentido poderia ser dado pela aplicação de uma série de testes e mensurações mentais a um grande número de indivíduos. Os resultados teriam grande valor científico, ao descobrir a constância de processos mentais, sua interdependência, e sua variação sob circunstâncias diferentes" (Herrnstein \& Boring, p. 522 , 1971). O caminho está aberto para a psicotécnica. Esse caminho se faz com a instituição de Ligas, Associações e Sociedades que estabelecem os parâmetros do conhecimento científico no país atrelados às demandas e convocações políticas e econômicas que se configuram na primeira metade do século XX.

É o caso da Sociedade Brasileira de Ciências, fundada em 1916 por engenheiros e médicos, principalmente, da Escola Politécnica do Rio de Janeiro, do Serviço Geológico e Mineralógico do Brasil, do Instituto Osvaldo Cruz e do Museu Nacional, de acordo com o 
Dicionário Histórico-Biográfico das Ciências da Saúde no Brasil entre os anos de 1832 até 1930. Esse Dicionário foi compilado por pesquisadores da Fundação Osvaldo Cruz e é disponibilizado virtualmente pela Fundação Osvaldo Cruz ${ }^{6}$. A SBC - Sociedade Brasileira de Ciências - surge em meio aos movimentos reformistas na ciência encabeçados pelas teorias de Einstein - sobre a Relatividade - em detrimento da física Newtoniana e do positivismo de Comte, tão em voga nos programas de desenvolvimento da nação naquele início de século.

Segundo os pesquisadores do Dicionário da Fiocruz, a fundação da SBC teve por objetivo reunir os intelectuais e cientistas que "reivindicavam melhores condições para o exercício da ciência pura”. Com isto, eles buscavam revitalizar a atividade científica no Brasil incentivando "trabalhos científicos originais, baseados na dedução lógica a partir da observação e experimentação empírica". Não desconsideravam a aplicabilidade de suas teorias na sociedade, antes, pressupunham que "os fins utilitários promovidos pela ciência é que mobilizavam a sociedade em geral a valorizar a atividade científica. " Mas, não perdiam a oportunidade de enfatizar que, "as grandes conquistas da humanidade só teriam sido possíveis com a concorrência da chamada 'ciência pura', embora suas aplicações em geral, não tivessem sido imediatas nem previsíveis". Os cientistas da Sociedade ao mesmo tempo que queriam reforçar o caminho de uma ciência pura e desinteressada que se contrapunha a uma ciência utilitária ou aplicada, empolgavam-se com as aplicações da ciência em seus artigos, tais como "a existência do petróleo, com relevância econômica explícita, e a dermatologia clínica alusivo a uma prestação de serviços". A estrutura da SBC dividia-se em três sessões: ciências matemáticas, ciências físico-químicas e ciências biológicas, em franco seguimento da Academia Francesa de Ciências voltada para as ciências naturais. E os seus sócios enquadravam-se em três categorias: beneméritos, aqueles que se considerava que haviam prestado um serviço relevante para a sociedade; honorários, os estrangeiros que tivessem notável merecimento e não residissem no país; e, efetivos, os sócios eleitos e fundadores da Sociedade Brasileira de Ciências. Havia também os associados e os correspondentes. Neste caso, consistia-se de assistentes para a discussão das matérias. Se residisse no Brasil seria um associado, se residisse fora do país seria um correspondente. Na fundação da SBC, 19 correspondentes foram nomeados; entre eles, encontravam-se Albert Einstein, George Dumas, Robert Ross, Henri Abraham, Émile Marchoux e Paul Janet. E um único sócio foi designado como benemérito: o Sr. André Gustavo Paulo de Frontin, o diretor da Escola Politécnica do Rio de Janeiro que sedia o espaço físico para as reuniões da agremiação. Em 1921, os sócios da SBC resolveram mudar o seu nome para Academia Brasileira de Ciência, temendo a marginalização da sociedade se outros colegas fundassem uma Academia nos mesmos 
moldes.

Como vimos apresentando até agora, as contribuições da psicologia, ancorada nas ciências biológicas e em um modelo científico positivista, ampliam-se no projeto eugênico e desenvolvimentista instaurado na primeira metade do século XX no país, com a fundação de instituições públicas e privadas para fomentar o desenvolvimento de pessoas através da educação e do trabalho. Elas foram criadas para investir, principalmente, na seleção e orientação profissional desse novo trabalhador especializado e disciplinado, como foi o caso da Fundação Getúlio Vargas no RJ. Sobre a FGV, sabemos que se trata de uma instituição privada, criada em 1944, por decreto-lei assinado por Getúlio Vargas - o então presidente do governo nacional - e com financiamento público. Tinha como objetivo a formação de pessoal qualificado para ingressar na administração pública e privada. É nessa instituição que se lança em 1949 a publicação dos Arquivos Brasileiros de Psicotécnica, por iniciativa do Instituto de Seleção e Orientação Profissional, um setor da FGV.

No Brasil, de acordo com o dualismo que separa ciências teóricas e ciências aplicadas, a psicotécnica encontra-se amplamente consolidada como a aplicação da psicologia científica no país. Basta ver, o que José Roberto Moreira, educador e intelectual vinculado ao serviço público, e o primeiro diretor do CBPE - Centro Brasileiro de Pesquisas Educacionais - um Centro de Pesquisas criado no INEP - Instituto Nacional de Estudos Pedagógicos - para fazer frente às demandas políticas do Estado na formação e pesquisa da educação para o desenvolvimento da nação ${ }^{7}$ nos moldes estadunidenses, escreve sobre a psicotécnica, no artigo: "A noção pluralista do fato psíquico" em 1951, no $3^{\circ}$ volume dos Arquivos Brasileiros de Psicotécnica: "o que há de científico em Psicologia, no sentido pluralista e operacional da ciência é, sobretudo, a Psicotécnica" (Moreira, p. 10, 1951). Mais adiante, no mesmo artigo, Moreira define a psicotécnica como "a disciplina que rege a aplicação aos problemas humanos, dos dados da Psicofisiologia, pelo emprego de um conjunto de métodos rigorosamente científicos e, principalmente, de métodos psicométricos”.

Com esse breve preâmbulo de articulações político-científicas, visualizamos na elaboração e divulgação dos Arquivos Brasileiros de Psicologia a produção do conhecimento entremeado nos jogos políticos e econômicos, como também na abordagem do elemento étnico-racial exposto em suas páginas. Ali encontramos uma versão unilateral do cientista que explica e resolve a questão étnico-racial nos ditames de uma objetividade científica que se pretende isenta das impurezas políticas e sociais, as quais maculariam a supremacia da ciência pura, ou ainda de uma subjetividade concernente à percepção fidedigna dos fenômenos psicossociais. 
Concluímos que, a questão étnico-racial é tratada pelo princípio da redução ao mesmo, ou seja, a diversidade de concepções e versões sobre as realidades entrevistas na gama étnica e racial se reduz a uma única forma de descrever e de explicar o real. O fazer científico estabelece categorias que por sua vez, legitima as versões publicadas por um veículo autorizado pela estrutura maquinal da ciência, em uma única forma viável de realidade. Isto porque a produção científica pressupõe que determina os parâmetros da realidade verdadeira, logo, a versão única sobre os grupos e elementos étnicos e raciais por conta das categorias, classificações e interpretações resultantes do trabalho dos pesquisadores. Resta, a partir desse estudo sobre o étnico-racial nas ciências psicológicas, a indagação a respeito de nossas práticas de pesquisa: como formalizar práticas que arrisquem e duvidem mais do pressuposto de obtenção da verdade sobre a realidade imposta pelos procedimentos utilizados na formalização da ciência?

\title{
THE ETHNICAL AND RACIAL ELEMENT IN THE PSYCHOLOGICAL SCIENCES: VERSIONS OF A (IM)PURE SCIENCE
}

\begin{abstract}
In this paper, we examine how psychology was conceived racial ethnic element as its object of study, through the publications made in the Brazilian Archives of Psychology between 1949 and 1990. For this, we make use of studies of Bruno Latour, Isabelle Stengers and Vinciane Despret to operate conceptually on the versions that stabilize the joints between science, politics and society. These authors displace production of knowledge from a traditional way of doing science and history to cosmopolitics approach of science. In articles researched, delimit four epistemological axes or stabilized forms that composed the scientific versions of ethnoracial in this study. They are: 1. Biological determinism; 2. Classification and measurement of natural sciences; 3 . The psychotecnique of the Attributes of Personality; 4. A Phenomenology of the cultural subject. We also present the political and scientific articulations that allowed the formation of the axes composing the versions of racial ethnic.

Keywords: Ethnic and Racial Diversity; Scientific Production; Cosmopolitics Science.
\end{abstract}

\section{EL ELEMENTO ÉTNICO-RACIAL EN LAS CIÊNCIAS PSICOLÓGICAS: VERSIONES DE UMA CIÊNCIA IM(PURA)}

\section{Resumen}

En este trabajo, se analiza como la psicologia fue concebiendo lo elemento étnico-racial como su objeto de estudio, a través de publicaciones realizadas en los Archivos Brasileiros de Psicologia entre 1949 y 1990. Para esto, hacemos uso de estudios de Bruno Latour, Vinciane Despret e Isabelle Stengers para operar conceptualmente en las versiones que se estabilizan en las articulaciones entre la ciencia, la política y la sociedad. Estos autores desplazan la producción de conocimiento desde una forma tradicional de hacer la ciencia y la historia para uno enfoque cosmopolítico de la ciencia. En los artículos investigados, delimitamos cuatro ejes epistemológicos o formas estabilizadas que componen las versiones científicas del 
elemento étnico-racial en este estudio. Ellos son: 1. El determinismo biológico; 2. Clasificación y valoración de las ciencias naturales; 3. Psycho-Técnicas de los atributos de la personalidad, y; 4. Una fenomenología del sujeto cultural. También presentamos las articulaciones político- científicas que permitieron la formación de los ejes que componen las versiones de lo étnico-racial.

Palabras-clave: Diversidad etnico-racial; Producción científica; Ciencia cosmopolítica.

\section{Referências:}

AUGRAS, M. O objeto do desejo. A identificação do dono da cabeça no candomblé. Arquivos Brasileiros de Psicologia. Rio de Janeiro, v.31, n.1, p. 37-52, 1979.

AUGRAS, M. Problemas teóricos (e metodológicos) da pesquisa psicológica em comunidades de terreiro. Arquivos Brasileiros de Psicologia. Rio de Janeiro, v. 37, n.1, p. 21-25, 1985.

AUGRAS, M. Testes psicológicos e antropologia. Arquivos Brasileiros de Psicologia. v. 42, n.3, p. 78-87, 1990.

BOTELHO, T. R. Censos e construção nacional no Brasil Imperial. Tempo Social, v. 17, n.1, p. 321-341, 2005.

CARVALHO, A. M. T. Trabalho e higiene mental: processo de produção discursiva do campo no Brasil. História, Ciências, Saúde - Manguinhos. v. 6, n.1, p. 133-156, 1999.

DANIEL, L. S. João Roberto Moreira (1912 - 1967): itinerários para uma racionalidade ativa. Tese de Doutorado. Programa de Pós-Graduação em Educação, Universidade Federal do Paraná, Curitiba, PR, 2009. Recuperado em 04 de novembro, 2013, de http://dspace.c3sl.ufpr.br/dspace/bitstream/handle/1884/17866/Leziany.pdf?sequence=1.

DESPRET, V. Le emozioni - etnopsicologia dell'autenticità. Milano: Elèuthera, 2002.

FIGUEIREDO, L. C. M. Matrizes do pensamento psicológico. $16^{\mathrm{a}}$ ed. Petrópolis, RJ: Vozes, 2010.

GINSBERG, A. M. Comparação entre os resultados de um teste de nível mental aplicado em diferentes grupos étnicos e sociais. Arquivos Brasileiros de Psicologia. v. 3, n.4, p. 27 44, 1951.

LAREZ, B. Os índios guaraunos através do psicodiagnóstico Miocinético do Dr. Mira y Lopez. Arquivos Brasileiros de Psicologia. v. 7, n.1, p. 29-40, 1955.

LATOUR, B. Jamais fomos modernos: ensaio de antropologia simétrica. Rio de Janeiro: 
Editora 34, 1994.

LATOUR, B. A esperança de pandora. Bauru: EDUSC, 2001.

LATOUR, B. Reagregando o social - uma introdução à teoria do Ator-Rede. Salvador: Edufba; São Paulo: Edusc, 2012.

LEVY, M. S. F. O papel da migração internacional na evolução da população brasileira (1872 a 1972). Revista de Saúde Pública. v. 8 (suplem.), p. 49-90, 1974.

LOBO, L. F. Os infames da história: pobres, escravos e deficientes no Brasil. Rio de Janeiro: Lamparina, 2008.

MIRA, A. G. Características de personalidade em dois grupos étnicos, através do psicodiagnóstico Miocinético. Arquivos Brasileiros de Psicologia. v. 20, n.2, p. 21-34, 1968.

MOREIRA, J. R. A noção pluralista de fato psíquico. Arquivos Brasileiros de Psicologia. v.3, n.1, p. 7-22, 1951.

PEREGALLI, E. Escravidão no Brasil. São Paulo: Global, 1988.

ROMANKIEWICZ, E. \& BUCHER, R. A estrutura psicopulsional de um grupo indígena brasileiro. Arquivos Brasileiros de Psicologia. v. 34, n.4, p. 95-112, 1982.

SBC - Sociedade Brasileira de Ciências. Dicionário histórico-biográfico das ciências da saúde no Brasil (1832 - 1930). Casa de Osvaldo Cruz/Fiocruz. Recuperado em 25 de setembro, 2013, de http://www.dichistoriasaude.coc.fiocruz.br.

STENGERS, I. A invenção das ciências modernas. São Paulo: Editora 34, 2002.

VILHENA, C. P. S. Práticas eugênicas, medicina social e família no Brasil republicano. Revista da Faculdade de Educação. v. 19, n.1, p. 79 -96, 1993.

ZILLES, U. Fenomenologia e Teoria do Conhecimento em Husserl. Revista da Abordagem Gestáltica. v. 12, n. 2, p. 216-221, 2007. Recuperado em 01 de setembro, 2015, de http://pepsic.bvsalud.org/pdf/rag/v13n2/v13n2a05.pdf

\footnotetext{
1 De acordo com a Publicação Crítica do Recenseamento Geral do Império do Brasil de 1872 realizado pelo Núcleo de pesquisa em História Econômica e Demográfica da UFMG e publicado em um Relatório Provisório em Janeiro de 2012. Recuperado em: 07/12/2015 de: http://www.nphed.cedeplar.ufmg.br/wpcontent/uploads/2013/02/Relatorio_preliminar_1872_site_nphed.pdf..

2 A revista foi editada pela Fundação Getúlio Vargas - FGV - até 1968 como Arquivos Brasileiros de
} 
Psicotécnica; a partir de 1968 até 1979, chamou-se Arquivos Brasileiros de Psicologia Aplicada. Desde então, intitula-se Arquivos Brasileiros de Psicologia. Em 1992 é assumida pelo PPG em Psicologia da UFRJ.

3 Como nas obras: Jamais fomos modernos (1994), A esperança de pandora (2001) e Reagregando o social (2012) de Bruno Latour; Le emozioni- etnopsicologia dell'autenticità (2002) de Vinciane Despret; ou ainda, A invenção das ciências modernas (2002) de Isabelle Stengers.

4 Arquivos Brasileiros de Psicologia.

5 De acordo com a compilação feita por Herrnstein \& Boring (1971) sobre textos voltados para uma ciência pura, neutra e quantitativa, que fizeram a história da psicologia. Textos Básicos de História da Psicologia. SP: Ed. Herder.

$6 \quad$ http://www.dichistoriasaude.coc.fiocruz.br.

$7 \quad$ Segundo o estudo de tese de Leziany Daniel, defendido em 2009 na UFPR, intitulado José Roberto Moreira (1912 - 1967): itinerários de uma racionalidade ativa.

Data de recebimento: 22/09/2016

Data de aceite: $23 / 03 / 2017$

Sobre as autoras:

Zuleika Köhler Gonzales é Professora do curso de Psicologia - UNISINOS/RS. Doutora em Psicologia social e institucional pela UFRGS. Endereço eletrônico: zuleika3012@yahoo.com.br

Neuza Maria Guareschi Correio possui graduação em Psicologia pela Pontifícia Universidade Católica do Rio Grande do Sul (1979), mestrado em Psicologia Social e da Personalidade pela Pontifícia Universidade Católica do Rio Grande do Sul (1991). Doutorado em Educação University of Wisconsin-Madison (1998). Pós-doutorado no Institute of Education na University College of London (2014). Endereço eletrônico: nmguares@ gmail.com 